\title{
An integrated literature review of undergraduate peer teaching in allied health professions
}

\author{
S van Vuuren, BOT, MOT, PhD Health Professions Education \\ School for Allied Health Professions and Department of Occupational Therapy, Faculty of Health Sciences, University of the Free State, Bloemfontein, South Africa
}

Corresponding author: S van Vuuren (alliedhealthfhs@ufs.ac.za)

Background. The concept of peer-assisted teaching or peer-assisted learning (PAL) has been receiving more attention in the teaching of medical and allied health students. Many advantages have been described in the literature, but much more research is needed. Challenges with the academic platform at a specific institution of higher learning necessitate investigation into the current literature on PAL, which can inform decisions in terms of teaching and learning of allied health professions students.

Objective. To critically appraise evidence of the effectiveness and implementation of PAL during the professional clinical skills training of undergraduate students in allied health professions to make informed future decisions on teaching and learning.

Methods. A literature search was conducted by an experienced librarian in the Faculty of Health Sciences, University of the Free State, Bloemfontein, South Africa and the researcher in multiple electronic databases (MEDLINE, CINAHL, Africa-Wide Information, ERIC and PubMed) published from 2000 to 2014.

Results. One hundred and seventy-five articles on PAL in health professions training were identified. The selected articles $(n=20)$ were independently critically appraised by two researchers by means of the standardised critical appraisal skills programme (CASP) and the Author Manuscript of the National Institutes of Health on Appraising Quantitative Research in Health Education. Nine articles were identified to be reviewed (two by the same author).

Conclusion. The findings with regard to the limited number of articles reviewed suggested that PAL may address some of the needs of the new generation of students and may be beneficial to the student tutor, student tutee and clinical supervisor. More evidence is needed in terms of the questions arising from the review, especially with regard to occupational therapy, dietetics and nutrition, and optometry, to fully implement PAL.

Afr J Health Professions Educ 2017;9(1):9-12. DOI:10.7196/AJHPE.2017.v9i1.588

Allied health professions programmes, in particular with regard to occupational therapy, physiotherapy, and dietetics and nutrition, share common traits in the structure of their clinical programmes. Each requires clinical experience for undergraduate students, which provides valuable hands-on patient care. From an educational viewpoint, the accreditation standards of the professional bodies and institutions of higher learning, to which the clinical training programmes must adhere, are also applicable. Acquiring these clinical professional skills needs clinical supervisors who must balance patient care with clinical instruction and supervision of students.

One strategy adopted in nursing and medicine to address the teaching of clinical skills is peer-assisted learning (PAL), which is well documented in especially nursing training programmes. ${ }^{[1-3]}$ Informal PAL has been practised for many years among students of all health professions, while formal or planned PAL became particularly prominent in medical education in recent years. ${ }^{[1]}$ PAL is increasingly being implemented in healthcare education for a variety of reasons, i.e. increased student numbers, teaching professional skills in a clinical setting, increasing focus on group training, and challenges with clinical supervision and placements. The literature indicates that in allied health professions PAL is under-researched, ${ }^{[3]}$ a view shared by Sevenhuysen et al. ${ }^{[4]}$ Martin and Edwards ${ }^{[5]}$ added that although the benefits of peer learning have been well documented in the educational literature, it is less so in health professions education. PAL in allied health professions is not as well documented as in medicine and nursing, although common principles are relevant for most clinical training courses. The terminology used to describe PAL is often submerged under a general label, ${ }^{[2]}$ such as informal teaching by senior students. For the purpose of this literature review, planned PAL is defined as peer tutoring and peer learning.

Boud $^{[6]}$ describes planned PAL as a two way reciprocal learning activity and should involve the sharing of knowledge, ideas. Topping ${ }^{[7]}$ added that PAL takes place among people of similar social groupings who are not professional teachers, helping each other to learn and learning themselves by teaching. Researchers are of the opinion that the benefits of this approach include reinforcement and revision of learning, provision of feedback, role-modelling, communication, appraisal and team-working skills. Curriculum developers also increasingly consider PAL as a vehicle to help undergraduate healthcare students learn to teach. ${ }^{[3]}$ It is further argued that the peer teachers have 'cognitive congruence', which allows these tutors to use language that their tutees understand and to explain concepts at an appropriate level..$^{[6,8]}$

In the USA, a recent study of 130 medical schools indicated that $76 \%$ use students in some form of PAL, and interest is growing in the field of PAL in medical and allied health professions. ${ }^{[8]}$ The reason for this interest is that PAL can be considered to address gaps in learning after assessment, and new learning outcomes or drivers from external and political requirements. In the UK, the lack of interest among some health professionals to pursue an academic career may be due to limited teaching skills. ${ }^{[1]}$ An article on the clinical education of physiotherapy students adds that the demand for clinical 
placements outstrips the supply of facilitators - and PAL can support clinical facilitators. ${ }^{[3]}$

The School for Allied Health Professions (SAHP), University of the Free State, Bloemfontein, South Africa currently offers four undergraduate programmes, i.e. nutrition and dietetics, occupational therapy, physiotherapy, and optometry. Investigation of the possibilities of PAL is necessitated by several factors, such as challenges in terms of the current academic platform for different stages of clinical training, the economic advantages for both the teaching institution and clinical fieldwork areas, enhancing the teaching skills of senior students, role-modelling for junior students, and increased collegial behaviour among different groupings of students. Planned PAL has been implemented as a pilot project in 2013 in the Department of Occupational Therapy as part of revisiting the current undergraduate curriculum and clinical training platforms. Another department is also investigating the possibilities to enhance the quality of teaching and learning owing to increased institutional research, other expectations of staff, and challenges with the availability of clinical supervisors in the public health sector. To assume that PAL will add to addressing these challenges, further investigation of the literature is necessary, as the best available evidence will inform/confirm current and future clinical teaching decisions regarding the training programmes in SAHP.

\section{Objective}

This integrated literature review was done by the researcher to appraise findings of the effectiveness and implementation of PAL (peer tutoring and peer learning) during the training of undergraduate students in allied health professions in professional clinical skills, contributing to informed future decisions on teaching and learning. The purpose of the literature review was to identify: (i) PAL in allied health profession programmes - professions that adopted PAL and level of students involved; (ii) the dimensions of PAL, which included training of tutors and tutees; formality of teaching encounter; evaluation of tutor and tutee; group size; outcome related to knowledge, skills and attitudes of tutors and tutees; strategies enabling implementation of PAL; and recommendations to improve PAL..$^{[1,2,8]}$

\section{Methods}

A literature search was conducted by an experienced librarian in the Faculty of Health Sciences and the researcher in multiple electronic databases (MEDLINE, CINAHL, Africa-Wide Information, ERIC and PubMed) from 2000 to 2014. The following keywords and phrases were used: peer-assisted teaching health sciences; PAL and undergraduate allied health professions; PAL and occupational therapy; PAL and physiotherapy; PAL and nutrition and dietetics; and PAL and optometry. One hundred and seventy-five articles on peer-assisted learning in health professions training were identified.

The selection criteria for the final review were as follows:

- articles on PAL for allied health professions undergraduate students as a group

- articles on PAL applicable to undergraduate students in nutrition and dietetics, occupational therapy, optometry and physiotherapy

- PAL teaching clinical professional skills

- full-text articles published in English

- articles of qualitative and quantitative nature

- articles related to undergraduate training.
The selected articles $(n=20)$ were independently critically appraised by two researchers by means of the standardised Critical Appraisal Skills Programme (CASP),${ }^{[9]}$ and the Author Manuscript of the National Institutes of Health on Appraising Quantitative Research in Health Education. ${ }^{[10]}$ Eight articles were identified to be reviewed. These nine articles referred only to occupational therapy and physiotherapy programmes. No research articles on PAL in nutrition and dietetics or optometry were retrieved. The other 12 articles were excluded as they described blogging and not person-to-person learning; PAL relating to postgraduate students and theory; collaborative learning (group work and problem-based learning); collaborative supervision models that included principles different from those of PAL; PAL in other professional groups; and peer support, mini literature descriptions and collaborative group support.

Ethical approval for the study was obtained from the Faculty of Health Sciences Ethics Committee according to faculty research policy (ref. no. EUFS 182/2014).

\section{Results}

This review was unable to provide conclusive evidence on PAL in allied health professions owing to the small number of relevant articles, lack of articles on nutrition and dietetics and optometry, difference in sample size, study population, and duration of implementation of PAL. The majority of the articles reflected PAL of physiotherapy undergraduate students. However, the articles reviewed agreed on most of the principles of PAL and can be used to guide the planning and implementation of PAL.

\section{PAL in allied health professions programmes}

Two of the articles were related to occupational therapy programmes ${ }^{[11,12]}$ and the remaining six to physiotherapy programmes. ${ }^{[13-18]}$ This indicated that knowledge on PAL in the allied health professions is limited.

The level of students participating in PAL indicated that experienced students mostly help inexperienced ones. Using PAL during the training of professional skills, the tutors and tutees should be senior students, ${ }^{[11,12,18]}$ but PAL could also be implemented during the first year of study in physiotherapy. ${ }^{[14]}$ One article conveyed the opinion that students from the same academic year could also assist. ${ }^{[12]}$ Evidence is needed for occupational therapy, dietetics and nutrition, and optometry to determine at what level of their programmes PAL will be most beneficial.

\section{Dimensions of PAL}

In this section the following is addressed: training of tutors and tutees; formality of the teaching encounter; evaluation of tutor and tutee; group size; outcome related to knowledge, skills and attitudes of tutors and tutees; strategies enabling implementation of PAL; and recommendations to improve PAL.

\section{Training of tutors and tutees}

Student preparation has frequently been cited as key for a successful PAL experience. Without training the tutors and tutees may not have the skills to make their collaborative relationship work. ${ }^{[13]}$ It is important to be explicit about what peer learning does/does not entail, and what it intends to achieve ${ }^{[14]} \mathrm{A}$ compulsory 2-hour tutorial session on peer coaching was hosted and students had to read an article on PAL in clinical education. ${ }^{[13]}$ In another study an introductory lecture was presented and a hand-out was 
given that covered information on the structure, aims, benefits, guidance on the roles of tutor and tutee, and what topics should be dealt with during $\mathrm{PAL},{ }^{[14]}$ and also understanding the group process, such as leadership, conflict management, decision-making and adult learning principles. ${ }^{[17]}$ During the preparation sessions, some tutors viewed PAL as positive, while others felt there was nothing to gain by helping fellow students and demonstrated resentment in parting with their own knowledge, ${ }^{[15]}$ or the development of competition that could result in disengagement among students. ${ }^{[16]}$

The literature confirms the importance of adequate preparation of students by instructors and students to accept peer tutors. ${ }^{[13,14,17]}$ Ladyshewsky ${ }^{[16]}$ proposed an eight-step model for the preparation of peer coaching, starting with assessment of compatibility and trust building; planning; formalising the process; defining the goals; clarifying facts and assumptions; exploring possibilities; gaining commitment to actions; offering support; and accountability. Previous research demonstrated that the preparation of students during training is very important and little is known about PAL in the training of other allied health professionals. Research is needed by these professions to establish whether some clinical skills and fieldwork settings are more appropriate for the implementation of PAL; what information should be shared with the clinical supervisors; and/or whether they need any training beforehand.

\section{Formality of the teaching encounter}

Planned peer teaching indicates that some formality during the planning and execution of formal encounters should be scheduled. Findings by Hammond et al. ${ }^{[14]}$ showed that PAL sessions should be organised and incorporated in the timetable and curriculum of students, and not be seen as an additional task, but enjoyed as self-directed tutoring sessions. ${ }^{[18]}$ Adequate preparation of those directly involved is necessary, which means that formal sessions for both the tutors and tutees are required and academic oversight should be maintained to ensure consistency and quality of teaching. ${ }^{[17]}$ Students also indicated that they felt that staff should be present at the sessions. ${ }^{[18]}$ Formal PAL has been demonstrated to reduce demands on clinical supervisors and to improve the overall clinical experience of students. ${ }^{[16]}$

\section{Evaluation of tutor and tutee}

Feedback is essential during learning and coaching, and tutors must understand the principles of formative feedback. Ladyshewsky ${ }^{[16]}$ was of the opinion that feedback is difficult to administer in PAL, as it often becomes evaluative and influences the experience. Providing formative feedback through key coaching questions will engage tutees to reflect on their clinical reasoning and practice. This approach preserves the integrity of the relationship and strenghtens it. Where PAL was used for preparation of formative assessment, ${ }^{[15]}$ a student who failed received immediate feedback and further practice time to rectify mistakes. It has been suggested that most student evaluation forms to be completed during clinical work should have a section on professional behaviour, and that PAL of both the tutor and the tutee could be assessed in this section. The following example was given: ${ }^{[16]}$

\section{Competency: Professional behaviour}

This demonstrates appropriate commitment to learning by:

- demonstrating a positive attitude (motivation) towards learning

- welcoming/seeking opportunities to gain new knowledge

- reviewing appropriate material related to, e.g. the clinical specialty.
Limited research has examined the preferences of tutors and tutees for assessment and feedback. Therefore, it would be helpful to determine if there should be instances where the tutor and tutees are assessed. However, to create an environment conducive to learning for both, the author is of opinion that it should only be part of the formative assessment.

Only two of the articles addressed the specific evaluation during PAL by means of a quantitative and a qualitative research study. ${ }^{[4,13]}$ Both these studies relate to physiotherapy programmes.

\section{Group size}

The literature describes a variation in group size of $1: 1,1: 2$ and $1: 3,^{[11,12,17]}$ although current trends refer to students working in pairs, i.e. a 1:1 learning experience. ${ }^{[6]}$ None of the remaining articles mentioned the group size, but referred to growing confidence of tutees as the session continued, and, taking into consideration that tutees have to master their own clinical skills, a 1:1 group size seems the most realistic. ${ }^{[16]}$

\section{Outcomes of PAL related to knowledge, skills and attitudes of tutors/tutees}

Tutors

Peer tutoring provides students with opportunities to develop teaching support skills and enables them to function on a higher cognitive level and transfer learning to new situations. ${ }^{[17]}$ These skills are very important for allied health professionals, as in many instances clients are taught new skills, exercises and precautionary measures, to name a few. Understanding the principles of adult learning is also important during professional interventions; PAL creates an opportunity to tutees to apply and practise these principles. Teaching other students has been reported as positive; it also helped to develop their own learning and reasoning. ${ }^{[1-13,18]}$ Added advantages include the promotion of collegial relationships between the students, ${ }^{[17]}$ and facilitating communication skills. ${ }^{[13,18]}$ Asghar ${ }^{[15]}$ indicated that students showed sensitivity and empathy with regard to providing feedback to their peers. Physiotherapy students were also of the opinion that it was an opportunity to revise their skills and even master skills that they had not mastered in previous years of training. ${ }^{[13,18]}$ This approach provides an added bonus for senior students to do revision during clinical placements, as some of the skills were taught in previous years and the full programme does not have sufficient free time for revision. Occupational therapy students reported that they viewed things from a different perspective after the PAL sessions and it increased their confidence in their own skills. ${ }^{[1]}$ The challenges described in the literature are clashes of personalities, ${ }^{[12]}$ negative attitudes of tutors related to the sharing of knowledge, ${ }^{[15]}$ and inconsistency in the level of support given. ${ }^{[11]}$

\section{Tutees}

Tutees' experience of PAL has been described as positive. PAL allowed them to focus on learning without fear of asking basic questions and reduced stress. ${ }^{[12,17,18]}$ Some individuals felt more confident approaching a peer leader than a staff member with questions. ${ }^{[18]}$

Many of the effects on the skills, knowledge and attitudes of tutors and tutees are similar, such as the mastery of skills; transfer of learning in the classroom; improvement of communication skills and collegial relationships; and facilitation of clinical reasoning. ${ }^{[1-13,18]}$ Tutees were also of the opinion that the PAL environment had been useful to clarify issues that 
they did not understand in the formal teaching sessions, and that it fostered positive attitudes towards the subject matter. ${ }^{[17]}$ Challenges during PAL were congruent with those experienced by tutors, except that advanced students might dominate the learning environment or competition between tutee and tutor might occur. With no regulation of the content of the sessions, the potential exists for incorrect information to be conveyed. ${ }^{[18]}$ The cohort of students in health sciences are competitive by nature. It should, however, be stressed that competition is frowned upon in the current clinical practice environment, and working together as a team is necessary for today's health professionals, which should be emphasised during this learning experience. ${ }^{[16]}$

\section{Strategies enabling implementation of PAL}

Although most articles elucidated the experiences and value of PAL, only one article gave a more detailed overview of the process of implementation. ${ }^{[16]}$ Aspects to address during implementation are facilitation of a positive interdependence between tutors and tutees; preparation of tutors in understanding adult learning principles and group processes, such as leadership, conflict management, decision-making, giving feedback, how to deliver information in a non-evaluative manner; and reflection on and evaluation of processes. Individual accountability should be fostered in both the tutor and tutee. The same article ${ }^{[16]}$ described the different stages and objectives in each stage of implementation. Other findings with regard to implementation included compilation of a hand-out for PAL, ${ }^{[11]}$ careful incorporation of time in the timetable and curriculum to train and orientate the tutors and tutees, ${ }^{[14]}$ collaboration of students in the writing of pre-placement packs, ${ }^{[12]}$ putting a control system of qualified professionals in place to ensure consistency of dissemination of information, and ensuring a mechanism for debriefing peer tutors and to clarify queries. ${ }^{[17]}$

\section{Recommendations to improve PAL}

Asking two people to coach each other does not necessarily guarantee success. Although all 175 articles reported on the value of PAL, more evidence-based practice and research are needed to promote tailor-made PAL for a specific programme. Questions still unanswered, according to the literature, include how learning is negotiated within PAL sessions, and whether PAL promotes informal group activities outside the classroom. Ongoing investment in student support will be needed and, in addition, strategies (social media such as blogs and Facebook) must be investigated to provide equivalent support to students in clinical placements outside the city to ensure parity across the whole student group. ${ }^{[1,14,16]}$ Limited literature on the implementation of PAL in occupational therapy and other allied health professions warrants more research about the planning and implementation of PAL for these programmes. Although deemed a positive learning strategy in nursing and medicine with more researched evidence available, allied health professions need their own evidence to inform their decisions on clinical teaching.

\section{Conclusion}

Since 2000, little has been published on occupational therapy, dietetics and nutrition, and optometry. Physiotherapy has investigated PAL slightly more often, but most of the research was grounded in the work of one researcher at a specific institution of higher learning. This limited literature acknowledges the need for more research on the topic, as the majority of findings in other health professions ${ }^{[1,2,4-6]}$ and the reviewed articles indicate that the value for staff, clinical placements and students' positive experiences outweigh the challenges.

Insufficient clinical placements and supervision for undergraduate students in occupational therapy, physiotherapy and other allied health professions, as well as sufficient time for staff in higher education to adhere to their different roles, are a reality in the South African context. Globally, there is a need for more innovative methods to teach professional skills to health professionals, in addition to the need and requirements to also give attention to other skills, such as leadership, communication skills and clinical reasoning. The findings in the limited number of articles reviewed show that PAL may address some of the needs of the new generation of students and may be beneficial for the student tutor, student tutee and clinical supervisor. More evidence on the questions that arise from the review, especially with regard to occupational therapy, dietetics and nutrition, and optometry, is needed to fully implement PAL.

\footnotetext{
1. Ross MT, Cameron HS. Peer assisted learning: A planning and implementation framework. AMEE Guide No. 30. Med Teach 2007;29(6):527-545. http://dx.doi.org/10.1080/01421590701665886

2. Field M, Burke JM, McAllister D, Lloyd DM. Peer-assisted learning: A novel approach to clinical skills learnin for medical students. Med Educ 2007;41(4):411-418. http://dx.doi.org/10.1111/j.1365-2929.2007.02713.x

3. Secomb J. A systematic review of peer teaching and learning in clinical education. J Clin Nurs 2008;17(6):703716. http://dx.doi.org/10.1111/j.1365-2702.2007.01954.x

4. Sevenhuysen SL, Nickson W, Farlie MK, Raitman L, Keating JL. The development of a peer assisted learning model for the clinical education of physiotherapy students. J Peer Learn 2013;6:30-45. http://ro.uow.edu.au/cgi/ viewcontent.cgi?article $=1068 \&$ context=ajpl (accessed 15 January 2015).

5. Martin M, Edwards L. Peer learning on fieldwork placements. Br J Occupational Ther 1998;61(6):249-252. http:// dx.doi.org/10.1177/030802269806100603

6. Boud D. Introduction: Making a move to peer learning. In: Boud D, Cohen R, Sampson J, eds. Peer Learning in Higher Education: Learning from Each Other. London: Kogan Page, 2001:1-20.

7. Topping KJ. The effectiveness of peer tutoring in further and higher education: A typology and review of the literature. High Educ 1996;32:321-345. http://dx.doi.org/10.1007/BF00138870

8. Burgess A, McGregor D, Mellis C. Medical students as peer tutors: A systematic review. BMC Med Educ 2014;14:115. http://dx.doi.org/10.1186/1472-6920-14-115

9. Maden-Jenkins M. CASP 2006. Literature Searching for Qualitative Studies and Quality Appraisal. Lancashire UK: Edge Hill University, 2006.

10. Jack L Jr, Hayes SC, Scharalda JG, et al. Appraising quantitative research in health education: Guidelines for public health educators. Health Promotion Practice 2010;11(2):161-165. http://dx.doi.org/10.1177/1524839909353023 11. Daniels N. Peer interactions and their benefits during occupational therapy practice placement education Br J Occupational Ther 2010;73(1):21-28. http://dx.doi.org/10.4276/030802210X12629548272664

12. Steele-Smith S, Amstrong M. 'I would take more students but...': Student supervision strategies. Br J Occupational Ther 2001;64(11):549-551.

13. Ladyshewsky RK. A quasi-experimental study of the differences in performance and clinical reasoning using individual learning versus reciprocal peer coaching. Physiother Theory Pract 2002;18(1):17-31. http://dx.doi. org/10.1080/095939802753570666

14. Hammond JA, Bitchell CP, Jones L, Bidgood P. A first year experience of student-directed peer-assisted learning Active Learn High Educ 2010;11(3):201-212. http://dx.doi.org/10.1177/1469787410379683

15. Asghar A. Reciprocal peer coaching and its use as a formative strategy for first-year students. Assess Eval High Educ 2010;35(4):403-417. http://dx.doi.org/10.1080/0260293090286283

16. Ladyshewsky RK. Building co-operation in peer coaching relationships: Understanding the relationships between reward structure, learner preparedness, coaching skill and learner engagement. Physiotherapy 2006;92(1):4-10. http://dx.doi.org/10.1016/j.physio.2005.11.005

17. Lekkas P, Larsen T, Kumar S, et al. No model of clinical education for physiotherapy students is superior to anothe A systematic review. Aust J Physiother 2007;53(1):19-28. http://dx.doi.org/10.1016/S0004-9514(07)70058-2

18. Sole G, Rose A, Bennet T, Jaques K, Rippon Z. A student experience of peer assisted study sessions in physiotherapy. J Peer Learn 2012;5:42-51. http://ro.uow.edu.au/cgi/viewcontent.cgi?article=1042\&context=ajp (accessed 6 January 2016).
} 